\title{
Multicomponent Synthesis of 1,2,3-Triazoles in Water Catalyzed by Copper Nanoparticles on Activated Carbon
}

\author{
Francisco Alonso, ${ }^{\mathrm{a} *}$ Yanina Moglie, ${ }^{\mathrm{a}}$ Gabriel Radivoy, ${ }^{\mathrm{b}}$ and Miguel Yus ${ }^{\mathrm{a} *}$ \\ a Departamento de Química Orgánica, Facultad de Ciencias and Instituto de Síntesis Orgánica (ISO) \\ Universidad de Alicante, Apdo. 99, 03080 Alicante, Spain \\ Fax: (+34) 965903549; phone: (+34) 965903548; e-mail: falonso@ua.es,yus@ua.es \\ b Departamento de Química, Instituto de Química del Sur (INQUISUR-CONICET), Universidad Nacional del Sur \\ Avenida Alem 1253, 8000 Bahía Blanca, Argentina
}

Received: ((will be filled in by the editorial staff))

Supporting information for this article is available on the WWW under http://dx.doi.org/10.1002/adsc.200\#\#\#\#\#.((Please delete if not appropriate))

\begin{abstract}
Copper nanoparticles on activated carbon have been found to effectively catalyse the multicomponent synthesis of 1,2,3-triazoles from different azide precursors, such as organic halides, diazonium salts, anilines and epoxides in water. The first one-pot transformation of an olefin into a triazole is also described. The catalyst is easy to prepare, very versatile and reusable at a low copper loading.
\end{abstract}

Keywords: Click chemistry; Copper nanoparticles; Cycloaddition; Heterogeneous catalysis; Triazoles, Water

Since the paramount discovery by the groups of Melda $^{[1]}$ and Sharpless ${ }^{[2]}$ of the copper(I)-catalyzed Huisgen ${ }^{[3]}$ 1,3-dipolar cycloaddition of organic azides and alkynes, a plethora of methods have flourished around this reaction. ${ }^{[4]}$ Enormous efforts have been devoted in order to maximize the general efficiency of the process adapted to the multiple and manifold applications of the resulting 1,2,3-triazoles. ${ }^{[4,5]}$ For instance, to reduce the amounts of copper in solution should be a priority, particularly for biological applications, due to its potential toxicity. ${ }^{[6]}$ In this sense, heterogeneous catalysts offer several advantages over the homogeneous counterparts, such as easy recovery, easy recycling, and enhanced stability. ${ }^{[7]}$ Charcoal, ${ }^{[8]}$ zeolites, ${ }^{[9]}$ montmorillonite, ${ }^{[10]}$ NHC-modified silica, ${ }^{[11]}$ polystyrene ${ }^{[12]}$ or chitosan ${ }^{[13]}$ are some of the supports used for copper(I) in the heterogeneous version of the title click reaction. Since the discovery that copper metal can be a source of the catalytic species, ${ }^{[14]}$ copper nanoparticles have also emerged as efficient heterogeneous and potentially reusable catalysts. ${ }^{[15]}$ All the aforementioned methodologies, however, involve pre-formed organic azides, for which the use of organic solvents (e.g., dioxane, toluene, DMF, dichloromethane, hexane) is, in general, mandatory. The in-situ generation of organic azides in the presence of the alkyne (three-component alkyne- azide cycloaddition) ${ }^{[16]}$ minimizes hazards derived from their isolation and handling, at the same time that avoids the time consuming and waste generation of an additional synthetic step. This version is especially interesting when performed under heterogeneous conditions in neat water. ${ }^{[17]}$ Despite the clear advantages of heterogeneous catalysis, the long and tedious procedures usually required for the heterogeneisation of copper preclude the widespread utilisation of this type of catalysts. Therefore, easyto-prepare and versatile heterogeneous copper catalysts that can efficiently catalyse the multicomponent 1,3-dipolar cycloaddition of organic azides and alkynes in water are welcome.

Our ongoing interest on the reactivity of active metals ${ }^{[18]}$ led us to the application of active copper [from of $\mathrm{CuCl}_{2} \cdot 2 \mathrm{H}_{2} \mathrm{O}, \mathrm{Li}$, and 4,4'-di-tertbutylbiphenyl (DTBB, cat.) in THF] in reduction reactions. ${ }^{[19]}$ More recently, we discovered that unsupported copper nanoparticles, generated as above but from anhydrous $\mathrm{CuCl}_{2}$, effectively catalyse the 1,3-dipolar cycloaddition of azides and terminal alkynes in short reaction times and in the absence of any stabilising additive or ligand. ${ }^{[20]}$ Notwithstanding the superior catalytic activity when compared with other commercially available copper sources, the copper nanoparticles underwent dissolution under the reaction conditions $\left(\mathrm{Et}_{3} \mathrm{~N}, \mathrm{THF}, 65^{\circ} \mathrm{C}\right)$ and could not be reused. We wish to present herein our findings on the 1,3-dipolar cycloaddition of alkynes and in-situgenerated azides, from different precursors, catalyzed by copper nanoparticles supported on activated carbon in water.

A variety of copper catalysts were prepared by addition of the support to a suspension of the recently prepared copper nanoparticles, the latter readily generated from copper(II) chloride, lithium metal, and a catalytic amount of DTBB (10 mol\%) in THF at room temperature. The catalysts were not subjected to any pre-treatment. Benzyl bromide (1a) and phenylacetylene (2a) were used as model substrates 
Table 1. Three-component 1,3-dipolar azide-alkyne cycloaddition catalyzed by copper on different supports. ${ }^{[\mathrm{a}]}$

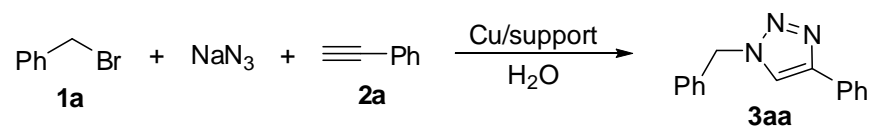

\begin{tabular}{lllll}
\hline Entry & Support $[\mathrm{mol} \% \mathrm{Cu}]^{[\mathrm{b}]}$ & $\begin{array}{l}T \\
{\left[{ }^{\circ} \mathrm{C}\right]}\end{array}$ & $t[\mathrm{~h}]$ & $\begin{array}{l}\text { Yield } \\
{[\%]^{[\mathrm{c}]}}\end{array}$ \\
\hline 1 & $\mathrm{SiO}_{2}[1]$ & 70 & 4 & $90(16)$
\end{tabular}

\begin{tabular}{lllll}
2 & $\mathrm{Al}_{2} \mathrm{O}_{3}[1]$ & 70 & 9 & $100(13)$ \\
3 & $\mathrm{TiO}_{2}[1]$ & 70 & 24 & 74 \\
4 & $\mathrm{MgO}[1]$ & 70 & 24 & 16 \\
5 & $\mathrm{ZnO}_{2}[1]$ & 70 & 24 & 57 \\
6 & $\mathrm{Al} \mathrm{silicate} \mathrm{[1]}$ & 70 & 6 & $100(19)$ \\
7 & $\mathrm{Al}[1]$ & 70 & 24 & 18 \\
8 & $\mathrm{MCM}-10[1]$ & 70 & 24 & 17 \\
9 & magnetite [1] & 70 & 9 & $100(0)$ \\
10 & graphite [5] & 70 & 14 & 80 \\
11 & graphite [5] & 70 & 24 & 0 \\
12 & graphite [5] & 25 & 24 & 33 \\
13 & graphite [1] & 25 & 24 & 31 \\
14 & graphite [1] & 70 & 7 & 90 \\
15 & MWCNT & $75]$ & 6 & $100(20)$ \\
16 & activated carbon [5] & 70 & 7 & 100 \\
17 & activated carbon [5] & 70 & 24 & 0 \\
18 & activated carbon [5] & 25 & 24 & 30 \\
19 & activated carbon [1] & 70 & 3 & $100(100)$ \\
20 & activated carbon [0] & 70 & 24 & $50^{[\mathrm{f}]}$ \\
\hline
\end{tabular}

[a] 1a (1 mmol), $\mathrm{NaN}_{3}(1.1 \mathrm{mmol})$, and 2a $(1 \mathrm{mmol})$ in $\mathrm{H}_{2} \mathrm{O}$. [b] Amount of copper added to the support. ${ }^{[\mathrm{c}]}$ GLC yield; the yield after a second cycle in parenthesis. ${ }^{[\mathrm{d}]}$ Solventfree reaction. ${ }^{[\mathrm{e}]}$ Multi-walled carbon nanotube. ${ }^{[\mathrm{f}]}$ As a 1:1.3 mixture of regioisomers; alkyne $19 \%$; azide $31 \%$.

in order to test the activity of the different catalysts (Table 1). $\mathrm{SiO}_{2}$ (entry 1), $\mathrm{Al}_{2} \mathrm{O}_{3}$ (entry 2), Al silicate (entry 6), magnetite (entry 9), graphite (entry 14), MWCNT (entry 15), and activated carbon (entry 19) led to yields $\geq 90 \%$ in $\leq 9 \mathrm{~h}$ at $70{ }^{\circ} \mathrm{C}$. Activated carbon, however, was shown to be more active $(100 \%$ yield, $3 \mathrm{~h})$ and the sole catalyst providing a quantitative yield of 3aa when reused in a second cycle (entry 19). When the cycloaddition was performed with activated carbon, in the absence of copper, a lower yield of the two regioisomeric triazoles was obtained (entry 20).

The copper-on-activated-carbon catalyst was characterized by different means. The copper content in the catalyst, $1.6 \mathrm{wt} \%$, was determined by inductively coupled plasma mass spectrometry (ICPMS). Analysis by TEM revealed the presence of spherical nanoparticles dispersed on the active carbon with diameters of ca. $6 \pm 2 \mathrm{~nm}$ (Figure 1). Energydispersive X-ray (EDX) analysis on various regions confirmed the presence of copper, with energy bands of $8.04,8.90 \mathrm{keV}$ (K lines) and $0.92 \mathrm{keV}$ (L line). The XRD diffractogram did not show any significant peak due to the amorphous character of the sample, to the fact that the crystal domains are $<10 \mathrm{~nm}$, and/or low copper loading weight. XPS analysis showed two $\mathrm{O}(1 \mathrm{~s})$ peaks at 532.2 and $534.2 \mathrm{eV}$, and three $\mathrm{Cu}$ $\left(2 \mathrm{p}_{3 / 2}\right)$ peaks at 934.1, 936.4, and $945.7 \mathrm{eV}$. From these results it can be inferred that the surface of the copper nanocatalyst is mainly oxidized. All peaks corresponding to the $\mathrm{Cu}\left(2 \mathrm{p}_{3 / 2}\right)$ level appear at higher binding energy when compared with those obtained with unsupported copper nanoparticles, ${ }^{[20]}$ with the peak at $945.7 \mathrm{eV}$ being a satellite shakeup feature characteristic of $\mathrm{Cu}^{2+}$ species. ${ }^{[1]}$ The selected-area electron-diffraction pattern (SAED) of the copper nanoparticles is also in agreement with the presence of $\mathrm{Cu}_{2} \mathrm{O}$ and $\mathrm{CuO}$. It is worthy of note that mixed $\mathrm{Cu} / \mathrm{Cu}$-oxide ${ }^{[15 c]}$ and, very recently, $\mathrm{CuO}$ nanostructures ${ }^{[22]}$ have been found to catalyse the 1,3 dipolar cycloaddition of azides and terminal alkynes.

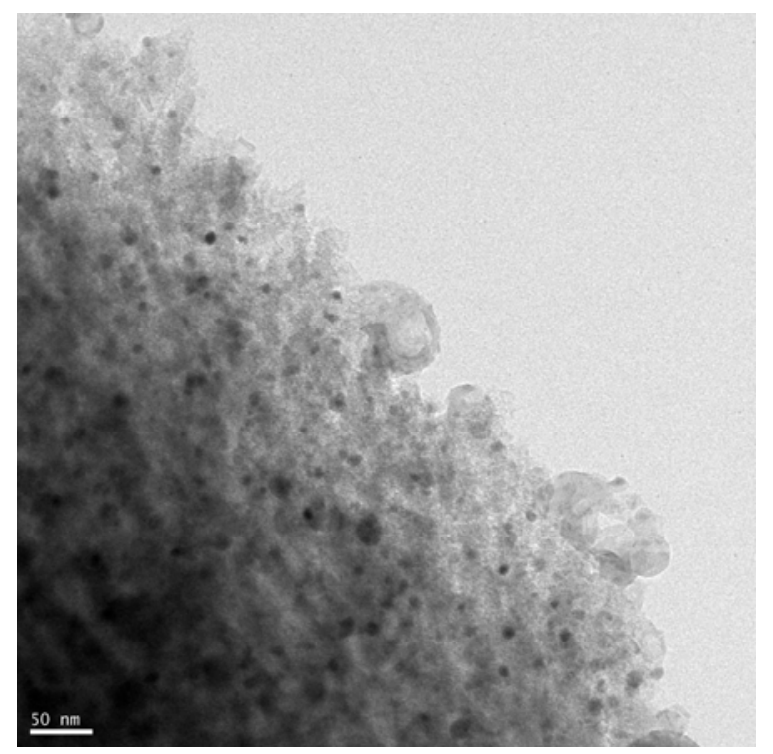

Figure 1. TEM micrograph of CuNPs on active carbon.

An array of activated organic halides (Table 2) was subjected to the three-component reaction with phenylacetylene in water at $70{ }^{\circ} \mathrm{C}$, using $0.5 \mathrm{~mol} \%$ CuNPs/C (Table 2, entries 1-6). Benzyl chloride reacted slower than the bromide counterpart albeit in excellent yield in both cases (entry 1). Benzyl bromides bearing either electron-withdrawing or electron-donating groups reacted nicely to furnish the corresponding triazoles in near quantitative yields (entries 2 and 3). A single product was obtained for cinnamyl bromide, with the intermediate azide not undergoing a [3,3]-sigmatropic rearrangement leading to the secondary allylic azide ${ }^{[23]}$ under the reaction conditions (Table 2, entry 4). Some activated functionalized organic halides, such as $\alpha$ chloroacetophenone (entry 5) or ethyl $\alpha$ bromoacetate (entry 6), were also studied, with the former reacting more sluggishly. Interestingly, not only activated but also deactivated alkyl halides could be used as the azide precursors in the title reaction (entries 7 and 8). A solvent system composed of $\mathrm{H}_{2} \mathrm{O}-\mathrm{EtOH} \mathrm{1:1}$ is, however, recommended in order to 
Table 2. Three-component 1,3-dipolar cycloaddition catalyzed by $\mathrm{CuNPs} / \mathrm{C}$ using organic halides as the azide precursors. ${ }^{[\mathrm{a}]}$

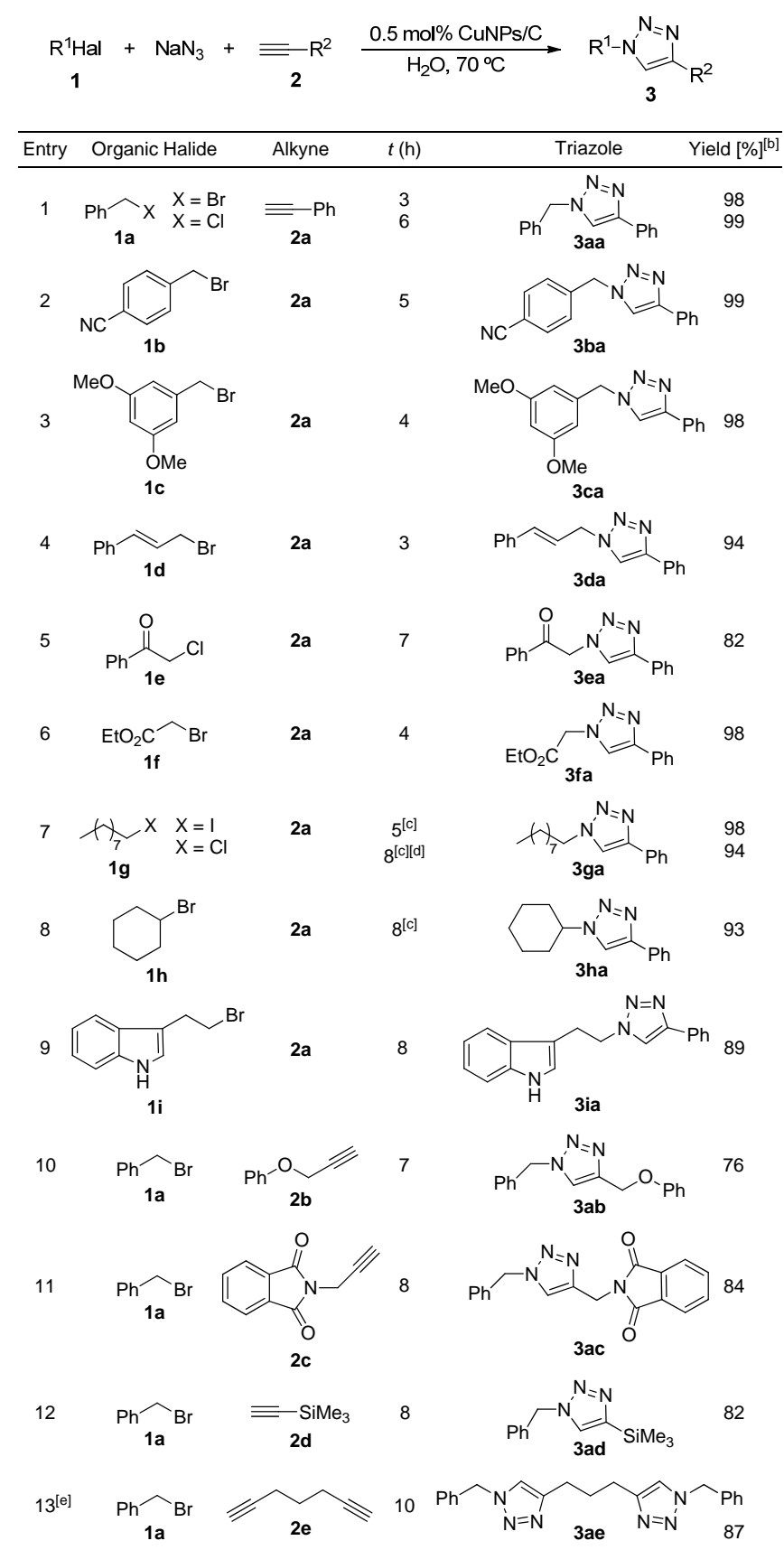

${ }^{\text {a] }}$ Reaction conditions: 1 (1 mmol), 2 (1 mmol), $\mathrm{NaN}_{3}(1.1$ mmol $), \mathrm{CuNPs} / \mathrm{C}(0.5 \mathrm{~mol} \%)$ in $\mathrm{H}_{2} \mathrm{O}(2 \mathrm{~mL})$ at $70{ }^{\circ} \mathrm{C}$. ${ }^{[b]}$ Isolated yield. ${ }^{[\mathrm{c}]}$ Reaction in $\mathrm{H}_{2} \mathrm{O}-\mathrm{EtOH} 1: 1{ }^{[\mathrm{d}]}$ Reaction at $100{ }^{\circ} \mathrm{C}$. ${ }^{[\mathrm{e}]} 2 \mathrm{mmol}$ of $\mathbf{1 a}$.

attain optimum results. $n$-Nonyl iodide (entry $7, \mathrm{X}=$ I) and cyclohexyl bromide (entry 8 ) reacted at $70^{\circ} \mathrm{C}$, whereas a temperature of $100{ }^{\circ} \mathrm{C}$ was required for the more reluctant to react $n$-nonyl chloride (entry $7, \mathrm{X}=$ Cl). The substrate 3-(2-bromoethyl)-1H-indole furnished the attractive doubly heterocyclic product 3ia (entry 9). The methodology also proved to be effective for alkynes other than phenylacetylene, such as phenyl propargyl ether (2b) or Npropargylphtalimide (2c) (entries 10 and 11, respectively). The successful reaction with trimethylsilylacetylene provides an indirect entry into the monosubstituted triazoles (after proper desilylation), making unnecessary the handling of acetylene (entry 12). Moreover, bistriazole 3ae was obtained in good yield from diyne $2 \mathbf{e}$ and two equivalents of benzyl bromide.

We next explored the possibility of using alternative substrates to the organic halides as azide precursors which, being compatible with the standard reaction conditions, could expand the versatility of the catalyst (Scheme 1). We were delighted to discover that epoxides reacted in water at $100{ }^{\circ} \mathrm{C}$ in a three-component mode, ${ }^{[24]}$ while other protocols require the sequential addition of reagents. ${ }^{[24]}$ As an example, styrene oxide was regioselectively transformed into the corresponding 2-substituted triazol-1-yl alcohol in high yield (Scheme 1). Diazonium salts, such as commercially available phenyldiazonium tetrafluoroborate, were utilized for the first time as potential substitutes of the less reactive aromatic halides (Scheme 1). Even more attractive was the four-component strategy involving an aromatic amine and tert-butyl nitrite at $70{ }^{\circ} \mathrm{C}$ (Scheme 1). This result is remarkable if we take into account that, in the only published method for this transformation, $t$-BuONO was used together with $\mathrm{TMSN}_{3}\left(\mathrm{NaN}_{3}\right.$ in our case) and applied sequentially in organic media. ${ }^{[25]}$ It is noteworthy that the reactivity of both, the diazonium salt and aniline, was comparable to that of benzyl bromide (2-3 h).

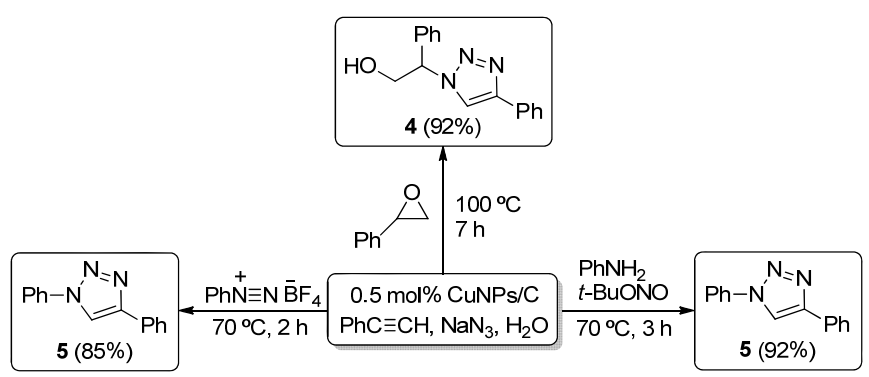

Scheme 1. Reaction of phenylacetylene with different azide precursors catalyzed by $\mathrm{CuNPs} / \mathrm{C}$ in water.

We were intrigued by the possibility of using haloalkynes, the derived azides of which might react either in an intramolecular or intermolecular fashion. Our expectations came to reality by subjecting 6chlorohex-1-yne to the standard reaction conditions (Scheme 2). The bicyclic triazole 6 was synthesized for the first time in a straight manner using click chemistry, while other reported procedures involved several synthetic steps. ${ }^{[2]}$ Furthermore, the transformation of alkenes into triazoles was also devised by taking advantage of the azasulfenylation of alkenes developed by Trost et al. ${ }^{[27]}$ In this methodology, an alkene was treated with dimethyl(methylthio)sulfonium tetrafluoroborate (DMTSF) at $0{ }^{\circ} \mathrm{C}$ to room temperature, followed by 
the addition of a nitrogen nucleophile at room temperature and stirring for 1-4 days. We applied a variation of this method in which the alkene was directly mixed with the CuNPs/C, DMTSF, and $\mathrm{NaN}_{3}$ in $\mathrm{MeCN}$ to produce the corresponding methylsulfanyl azide in only $1 \mathrm{~h}$ at room temperature. The subsequent reaction with the alkyne represents, to the best of our knowledge, the first example of triazole synthesis from an alkene in one pot (Scheme 3 ). The conditions and yield were not optimized yet but it seems a promising route to directly transform carbon-carbon double bonds into triazoles bearing a versatile methylsulfanyl group.

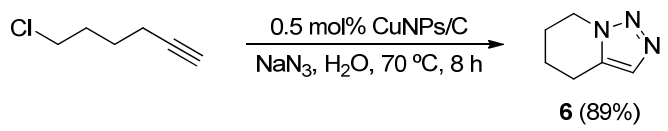

Scheme 2. Intramolecular three-component click reaction catalyzed by $\mathrm{CuNPs} / \mathrm{C}$ in water.

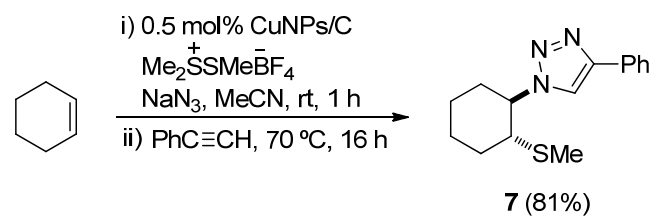

Scheme 3. One-pot multicomponent synthesis of a 1,2,3triazole from cyclohexene catalyzed by $\mathrm{CuNPs} / \mathrm{C}$.

It is worthwhile mentioning that all the reactions were carried out without air exclusion. Furthermore, reactions at a higher dilution, such as $0.1 \mathrm{M}$ or even $0.01 \mathrm{M}$, also afforded the expected triazoles in high yields, albeit longer reaction times were required (i.e., 8 and $24 \mathrm{~h}$, respectively, for benzyl bromide and phenylacetylene). In addition, the catalyst could be easily recovered by filtration and reused, leading to triazole 3aa in quantitative yield along five consecutive cycles. No leaching of copper was detected after the fifth cycle (ICP-MS). Nonetheless, in order to test the robustness of the catalyst and unveil the nature of the catalysis, the reaction of benzyl bromide and phenylacetylene was run up to a $100 \%$ conversion $(<3 \mathrm{~h})$, and the resulting mixture containing the triazole was subjected to additional heating until a total time of $24 \mathrm{~h}$. Then, the catalyst and the triazole were filtered off, the aqueous phase was extracted with ethyl acetate and fresh starting materials were again added to the resulting aqueous phase, which were allowed to react at $70{ }^{\circ} \mathrm{C}$ for $24 \mathrm{~h}$. A ca. 1:1 mixture of the corresponding regioisomeric triazoles was obtained with $17 \%$ conversion, thereby indicating that, in this case, the cycloaddition proceeded uncatalyzed under thermal conditions. ICP-MS analyses of the resulting aqueous phase gave $<50 \mathrm{ppb}$ of copper. These results point to a process of heterogeneous nature.

Finally, we compared the CuNPs/C catalyst with commercially available $\mathrm{Cu}, \mathrm{Cu}_{2} \mathrm{O}$, and $\mathrm{CuO}$ in the reaction of benzyl bromide and phenylacetylene under the standard conditions at 10 and $1 \mathrm{~mol} \%$ catalyst loading. Interestingly, $10 \quad \mathrm{~mol} \% \quad \mathrm{Cu}_{2} \mathrm{O}$ reached a maximum $90 \%$ conversion, albeit side products $(10 \%)$ were also obtained and its reutilisation furnished the corresponding triazole in $20 \%$ conversion after $24 \mathrm{~h}$ as a ca. $4: 1$ mixture of regioisomers. Therefore, the nanosized character of our catalyst makes all the difference.

In conclusion, we have presented a new heterogeneous catalyst for the multicomponent Huisgen 1,3-dipolar cycloaddition in water. The catalyst consists of oxidized copper nanoparticles on activated carbon and it is readily prepared from commercially available chemicals under mild conditions. The $\mathrm{CuNPs} / \mathrm{C}$, at a low catalyst loading $(0.5 \mathrm{~mol} \%)$, manifested a high versatility as not only organic halides, but other azide precursors, including epoxides, diazonium salts, anilines, or alkenes, could be successfully transformed into the corresponding 1,2,3-triazoles. The catalyst is reusable and seemingly operates under heterogeneous conditions. Further research to extend the substrate scope and better understand the catalysis is under way.

\section{Experimental Section}

\section{Typical procedure for the preparation of $\mathrm{CuNPs} / \mathrm{C}$}

Anhydrous copper(II) chloride (135 mg, $1 \mathrm{mmol})$ was added to a suspension of lithium (14 mg, $2 \mathrm{mmol}$ ) and 4,4'di-tert-butylbiphenyl (DTBB, $27 \mathrm{mg}, 0.1 \mathrm{mmol}$ ) in THF (2 $\mathrm{mL}$ ) at room temperature under an argon atmosphere. The reaction mixture, which was initially dark blue, rapidly changed to black, indicating that the suspension of copper nanoparticles was formed. This suspension was diluted with THF $(18 \mathrm{~mL})$ followed by the addition of the activated carbon $(1.28 \mathrm{~g})$. The resulting mixture was stirred for $1 \mathrm{~h}$ at room temperature, filtered, and the solid successively washed with water $(20 \mathrm{~mL})$, THF $(20 \mathrm{~mL})$ and dried under vaccum.

\section{General procedure for three-component 1,3-dipolar cycloaddition catalyzed by $\mathrm{CuNPs} / \mathrm{C}$ in water}

$\mathrm{NaN}_{3}(72 \mathrm{mg}, 1.1 \mathrm{mmol}$ ), the azide precursor (organic halide, diazonium salt, or epoxide, $1 \mathrm{mmol}$ ) and the alkyne $(1 \mathrm{mmol})$ were added to a suspension of CuNPs/C $(20 \mathrm{mg}$, $0.5 \mathrm{~mol} \% \mathrm{Cu})$ in $\mathrm{H}_{2} \mathrm{O}(2 \mathrm{~mL})$. The reaction mixture was warmed to $70{ }^{\circ} \mathrm{C}$ and monitored by TLC until total conversion of the starting materials. Water $(30 \mathrm{~mL})$ was added to the resulting mixture followed by extraction with EtOAc $(3 \times 10 \mathrm{~mL})$. The collected organic phases were dried with $\mathrm{MgSO}_{4}$ and the solvent was removed in vacuo to give the corresponding triazole, which did not require any further purification (except compounds 3ia and 7).

\section{Acknowledgements}

This work was generously supported by the Spanish Ministerio de Ciencia e Innovación (MICINN; CTQ2007-65218 and Consolider Ingenio 2010-CSD2007-00006), the Generalitat Valenciana (GV; PROMETEO/2009/039). Y.M. acknowledges the Vicerrectorado de Investigación, Desarrollo e Innovación of the Universidad de Alicante for a grant. 


\section{References}

[1] C. W. Tornøe, C. Christensen, M. Meldal, J. Org. Chem. 2002, 67, 3057-3064.

[2] V. V. Rostovtsev, L. G. Green, V. V. Fokin, K. B. Sharpless, Angew. Chem. 2002, 114, 2708-2711; Angew. Chem. Int. Ed. 2002, 41, 2596-2599.

[3] a) R. Huisgen, G. Szeimies, L. Moebius, Chem. Ber. 1965, 98, 4014-4021; b) R. Huisgen, Pure Appl. Chem. 1989, 61, 613-628.

[4] For reviews, see: a) V. D. Bock, H. Hiemstra, J. H. van Maarseveen, Eur. J. Org. Chem. 2006, 51-68; b) M. Meldal, C. W. Tornøe, Chem. Rev. 2008, 108, 2952-3015; c) P. Appukkuttan, E. Van der Eycken, Eur. J. Org. Chem. 2008, 1133-1155; d) C. O. Kappe, E. Van der Eycken, Chem. Soc. Rev. 2010, 39, 12801290.

[5] For recent reviews, see: a) M. V. Gil, M. J. Arévalo, O. López, Synthesis 2007, 1589-1620; b) J. E. Moses, A. D. Moorhouse, Chem. Soc. Rev. 2007, 36, 12491262; c) H. Nandivada, X. Jiang, J. Lahann, $A d v$. Mater. 2007, 19, 2197-2208; d) J.-F. Lutz, Angew. Chem. Int. Ed. 2007, 46, 1018-1025; e) A. Dondoni, Chem. Asian J. 2007, 2, 700-708; f) J.-F. Lutz, Z. Zarafshani, Adv. Drug Delivery Rev. 2008, 60, 958970; g) G. C. Tron, T. Pirali, R. A. Billington, P. L. Canonico, G. Sorba, A. A. Genazzani, Med. Res. Rev. 2008, 28, 278-308; h) A. D. Moorhouse, J. E. Moses, ChemMedChem 2008, 3, 715-723; i) for an special issue on applications of click chemistry, see: M. G. Finn, V. Fokin, Eds., Chem. Soc. Rev. 2010, issue $n^{\circ}$ 4.

[6] See, for instance: a) M. K. Holland, I. L. Pike, J. Reprod. Fert 1978, 53, 335-339; b) R. Wang, X.-T. Wang, L. Wu, M.-A. Mateescu, J. Toxicol. Environ. Health Part A 1999, 57, 507-519; c) M. K. Rauf, Imtiaz-ud-Din, A. Badshah, M. Gielen, M. Ebihara, D. de Vos, S. Ahmed, J. Inorg. Biochem. 2009, 103, 1135-1144; d) M.-L. Teyssot, A.-S. Jarrouse, A. Chevry, A. De Haze, C. Beaudoin, M. Manin, S. P. Nolan, S. Diez-Gonzalez, L. Morel, A. Gautier, Chem. Eur. J. 2009, 15, 314-318.

[7] a) Supported metals in catalysis (Eds.: J. A. Anderson, M. Fernández García), Imperial College Press, London, 2005; For a review, see: b) K. Kaneda, K. Ebitani, T. Mizugaki, K. Mori, Bull. Chem. Soc. Jpn. 2006, 79, 981-1016.

[8] a) B. H. Lipshutz, B. R. Taft, Angew. Chem. 2006, 118, 8415-8418; Angew. Chem. Int. Ed. 2006, 45, 8235-8238; b) C.-T. Lee, S. Huang, B. H. Lipshutz, Adv. Synth. Catal. 2009, 351, 3139-3142.

[9] a) S. Chassaing, A. S. S. Sido, A. Alix, M. Kumarraja, P. Pale, J. Sommer, Chem. Eur. J. 2008, 14, 67136721; b) S. Chassaing, A. Alix, T. Boningari, K. S. S. Sido, M. Keller, P. Kuhn, B. Louis, J. Sommer, P. Pale, Synthesis 2010, 1557-1567.

[10] I. Jlalia, H. Elamari, F. Meganem, J. Herscovici, C. Girard, Tetrahedron Lett. 2008, 49, 6756-6758.
[11] P. Li, L. Wang, Y. Zhang, Tetrahedron 2008, 64, 10825-10830.

[12] U. Sirion, Y. J. Bae, B. S. Lee, D. Y. Chi, Synlett 2008, 2326-2330.

[13] M. Chtchcigrovsky, A. Primo, P. Gonzalez, K. Molvinger, M. Robitzer, F. Quignard, F. Taran, Angew. Chem. 2009, 121, 6030-6034; Angew. Chem. Int. Ed. 2009, 48, 5916-5920.

[14] a) F. Himo, T. Lovell, R. Hilgraf, V. V. Rostovtsev, L. Noodleman, K. B. Sharpless, V. V. Fokin, J. Am. Chem. Soc. 2005, 127, 210-216; b) N. Gommermann, A. Gehrig, P. Knochel, Synlett 2005, 2796-2798.

[15] a) L. Durán Pachón, J. H. van Maarseveen, G. Rothenberg, Adv. Synth. Catal. 2005, 347, 811-815; b) H. A. Orgueira, D. Fokas, Y. Isome, P. C.-M. Chan, C. M. Baldino, Tetrahedron Lett. 2005, 46, 29112914; c) G. Molteni, C. L. Bianchi, G. Marinoni, N. Santo, A. Ponti, New J. Chem. 2006, 30, 1137-1139; d) A. Sarkar, T. Mukherjee, S. Kapoor, J. Phys. Chem. C 2008, 112, 3334-3340; e) I. S. Park, M. S. Kwon, Y. Kim, J. S. Lee, J. Park, Org. Lett. 2008, 10, 497500.

[16] a) P. Appukkuttan, W. Dehaen, V. V. Fokin, E. Van der Eycken, Org. Lett. 2004, 6, 4223-4225; b) Y.-B. Zhao, Z.-Y. Yan, Y.-M. Liang Tetrahedron Lett. 2006, 47, 1545-1549; c) K. Odlo, E. A. Høydahl, T. V. Hansen, Tetrahedron Lett. 2007, 48, 2097-2099; d) B. Saha, S. Sharma, D. Sawant, B. Kundu, Synlett 2007, 1591-1594; e) K. Yamaguchi, M. Kotani, K. Kamata, N. Mizuno, Chem. Lett. 2008, 37, 1258 1259; f) T. Miao, L. Wang, Synthesis 2008, 363-368; g) D. Kumar, G. Patel, V. B. Reddy, Synlett 2009, 399-402; h) A. R. Bogdan, N. W. Sach, Adv. Synth. Catal. 2009, 351, 849-854; i) D. Kumar, V. Buchi Reddy, R. S. Varma, Tetrahedron Lett. 2009, 50, 2065-2068.

[17] a) M. Laksmi Kantam, V. Swarna Jaya, B. Sreedhar, M. Mohan Rao, B. M. Choudary, J. Mol. Catal. A: Chem. 2006, 256, 273-277; b) H. Sharghi, R. Khalifeh, M. M. Doroodmand, Adv. Synth. Catal. 2009, 351, 207-218; c) V. Bénéteau, A. Olmos, T. Boningari, J. Sommer, P. Pale, Tetrahedron Lett. 2010, 51, 3673-3677.

[18] a) For reviews, see: a) F. Alonso, G. Radivoy, M. Yus, Russ. Chem. Bull., Int. Ed. 2003, 52, 2563-2576; b) F. Alonso, M. Yus, Chem. Soc. Rev. 2004, 33, 284-293; c) F. Alonso, M. Yus, Pure Appl. Chem. 2008, 80, 1005-1012.

[19] a) F. Alonso, C. Vitale, G. Radivoy, M. Yus, Synthesis 2003, 443-447; b) F. Alonso, Y. Moglie, G. Radivoy, C. Vitale, M. Yus, Appl. Catal. A: Gen. 2004, 271, 171-176; c) G. Radivoy, F. Alonso, Y. Moglie, C. Vitale, M. Yus, Tetrahedron 2005, 61, 3859-3864.

[20] a) F. Alonso, Y. Moglie, G. Radivoy, M. Yus, Tetrahedron Lett. 2009, 50, 2358-2362; b) F. Alonso, Y. Moglie, G. Radivoy, M. Yus, Eur. J. Org. Chem. 2010, 1875-1884. 
[21] K. V. R. Chary, G. V. Sagar, C. S. Srikhanth, V. V. Rao, J. Phys. Chem. B., 2007, 111, 543-550.

[22] J. Y. Kim, J. C. Park, H. Kang, H. Song, K. H. Park, Chem. Commun. 2010, 46, 439-441.

[23] A. K. Feldman, B. Colasson, K. B. Sharpless, V. V. Fokin, J. Am. Chem. Soc. 2005, 127, 13444-13445.

[24] a) K. Rajender Reddy, C. Uma Maheswari, K. Rajgopal, M. Laksmi Kantam, Synth. Commun. 2008, 38, 2158-2167; b) H. Sharghi, M. H. Beyzavi, A. Safavi, M. M. Doroodmand, R. Khalifeh, Adv. Synth. Catal. 2009, 351, 2391-2010.
[25] K. Barral, A. D. Moorhouse, J. E. Moses, Org. Lett. 2007, 9, 1809-1811.

[26] P. C. Montevecchi, M. L. Navacchia, P. Spagnolo, Eur. J. Org. Chem. 1998, 1219-1226; b) B. Abarca, R. Ballesteros, M. Elmasnouyb, Tetrahedron 1999, 55, 12881-12884; c) J. S. Clark, P. B. Hodgson, M. D. Goldsmith, L. J. Street, J. Chem. Soc., Perkin Trans. 1 2001, 3312-3324.

[27] B. M. Trost, T. Shibata, J. Am. Chem. Soc. 1982, 104, 3225-3228. 
Multicomponent Synthesis of 1,2,3-Triazoles in Water Catalyzed by Copper Nanoparticles on

Activated Carbon

Adv. Synth. Catal. Year, Volume, Page - Page

$\mathrm{R}^{1} \mathrm{X}+\mathrm{NaN}_{3}+\equiv \mathrm{R}^{2} \stackrel{0.5 \mathrm{~mol} \% \mathrm{CuNPs} / \mathrm{C}}{\mathrm{H}_{2} \mathrm{O}, 70^{\circ} \mathrm{C}} \rightarrow \mathrm{R}^{1}-\mathrm{N}^{\mathrm{N}} \stackrel{\mathrm{N}=\mathrm{N}}{=} \mathrm{R}^{2}$ $\mathrm{X}=\mathrm{Cl}, \mathrm{Br}, \mathrm{I}, \stackrel{+}{\mathrm{N}} \equiv \mathrm{N} \overline{\mathrm{B}} \mathrm{F}_{4}, \mathrm{NH}_{2}$, others

F. Alonso, ${ }^{*}$ Y. Moglie, G. Radivoy, M. Yus* 


\title{
Multicomponent Synthesis of 1,2,3-Triazoles in Water Catalyzed by Copper Nanoparticles on Activated Carbon
}

\author{
Francisco Alonso, ${ }^{\mathrm{a} *}$ Yanina Moglie, Gabriel Radivoy, ${ }^{\mathrm{b}}$ and Miguel Yus ${ }^{\mathrm{a} *}$ \\ ${ }^{a}$ Departamento de Química Orgánica, Facultad de Ciencias and Instituto de Síntesis Orgánica (ISO), \\ Universidad de Alicante, Apdo. 99, 03080 Alicante (Spain) \\ ${ }^{\mathrm{b}}$ Departamento de Química, Instituto de Química del Sur (INQUISUR-CONICET), Universidad \\ Nacional del Sur, Avenida Alem 1253, 8000 Bahía Blanca (Argentina)
}

\section{Supporting Information}

\section{General}

Anhydrous copper(II) chloride (Aldrich), lithium powder (MEDALCHEMY S. L.), DTBB (4,4'-ditert-butylbiphenyl, Aldrich), activated charcoal (Norit CA1, Aldrich), and sodium azide (Across) were commercially available. All the starting materials and other reagents were commercially available of the best grade (Aldrich, Acros, Alfa Aesar) and were used without further purification. THF was dried in a Sharlab PS-400-3MD solvent purification system using an alumina column. Melting points were obtained with a Reichert Thermovar apparatus. NMR spectra were recorded on Bruker Avance 300 and 400 spectrometers (300 and $400 \mathrm{MHz}$ for ${ }^{1} \mathrm{H}$ NMR; 75 and $100 \mathrm{MHz}$ for ${ }^{13} \mathrm{C} \mathrm{NMR}$ ); chemical shifts are given in $(\delta)$ parts per million and coupling constants $(J)$ in hertz. Mass spectra (EI) were obtained at $70 \mathrm{eV}$ on an Agilent 5973 spectrometer; fragment ions in $\mathrm{m} / \mathrm{z}$ with relative intensities (\%) in parenthesis. HRMS analyses were carried out on a Finnigan MAT95S spectrometer. The purity of volatile compounds and the chromatographic analyses (GLC) were determined with a Hewlett Packard HP-6890 instrument equipped with a flame ionization detector and a $30 \mathrm{~m}$ capillary column $(0.32 \mathrm{~mm}$ diameter, $0.25 \mu \mathrm{m}$ film thickness $)$, using nitrogen $(2 \mathrm{~mL} / \mathrm{min})$ as carrier gas, $T_{\text {injector }}=270{ }^{\circ} \mathrm{C}, T_{\text {column }}=$ $60{ }^{\circ} \mathrm{C}(3 \mathrm{~min})$ and $60-270{ }^{\circ} \mathrm{C}\left(15^{\circ} \mathrm{C} / \mathrm{min}\right)$; retention times $\left(t_{\mathrm{r}}\right)$ are given in min. Column chromatography was performed using silica gel 60 of 40-60 microns (hexane/EtOAc as eluant).

The TEM image was recorded using a JEOLJEM2010 microscope, equipped with a lanthanum hexaboride filament, operated at an acceleration voltage of $200 \mathrm{kV}$. For their observation, the samples were mounted on holey-carbon coated gold grid. X-EDS analyses were carried out with an Oxford Inca Energy TEM100 attachment. The XRD diffractogram was collected in the $\theta-\theta$ mode using a Bruker D8 Advance X-ray diffractometer: $\mathrm{Cu} \mathrm{K} \alpha_{1}$ irradiation, $\lambda=1.5406 \AA$; room temperature $\left(25^{\circ} \mathrm{C}\right) ; 2 \theta=$ 4-80. The XPS spectra were measured with a VG-Microtech Multilab 3000 electron spectrometer using a non-monochromatized $\mathrm{Mg}-\mathrm{K} \alpha(1253.6 \mathrm{eV})$ radiation source of $300 \mathrm{~W}$ and a hemispheric 
electron analyzer equipped with 9 channeltron electron multipliers. The pressure inside the analysis chamber during the scans was about $5 \cdot 10^{-7} \mathrm{~N} \cdot \mathrm{m}^{-2}$. After the survey spectra were obtained, higher resolution survey scans were performed at pass energy of $50 \mathrm{eV}$. The intensities of the different contributions were obtained by means of the calculation of the integral of each peak, after having eliminated the baseline with $\mathrm{S}$ form and adjusting the experimental curves to a combination of Lorentz (30\%) and Gaussian (70\%) lines. All the bond energies were referred to the line of the C 1s to 284.4 $\mathrm{eV}$, obtaining values with a precision of $\pm 0.2 \mathrm{eV}$. Inductively coupled plasma mass spectrometry (ICP-MS) analyses were carried out on a Thermo Elemental VG PQ Excell according to the following parameters: Gas flows, cool (14.00 bar), auxiliar (0.95 bar), nebulizer (0.90 bar), liquid flow (1 $\mathrm{ml} / \mathrm{min})$, dwell time (10000 $\mu \mathrm{s})$, sweeps (40), channels per mass (3), channel spacing (0.02), main runs (3), forward power $(1350 \mathrm{w})$.

\section{Typical procedure for the preparation of $\mathrm{CuNPs} / \mathrm{C}$}

Anhydrous copper(II) chloride (135 mg, $1 \mathrm{mmol}$ ) was added to a suspension of lithium powder (14 mg, $2 \mathrm{mmol}$ ) and 4,4'-di-tert-butylbiphenyl (DTBB, $27 \mathrm{mg}, 0.1 \mathrm{mmol}$ ) in THF (2 mL) at room temperature under an argon atmosphere. The reaction mixture, which was initially dark blue, rapidly changed to black (ca. 5-10 min), indicating that the suspension of copper nanoparticles was formed. This suspension was diluted with THF $(18 \mathrm{~mL})$ followed by the addition of the activated carbon $(1.28 \mathrm{~g})$. The resulting mixture was stirred for $1 \mathrm{~h}$ at room temperature, filtered, and the solid successively washed with water $(20 \mathrm{~mL})$, THF $(20 \mathrm{~mL})$, and dried under vaccum (15 Torr). When the copper nanoparticles were generated in the presence of the active carbon, the resulting catalyst was shown to be less effective in the click reaction.

\section{Characterization of the catalyst}

The $\mathrm{CuNPs} / \mathrm{C}$ was characterized by transmission electron microscopy with energy-dispersive X-ray analysis (TEM-EDX), selected area electron diffraction (SAED), X-ray photoelectron spectroscopy (XPS), and X-ray powder diffraction (XRD). 


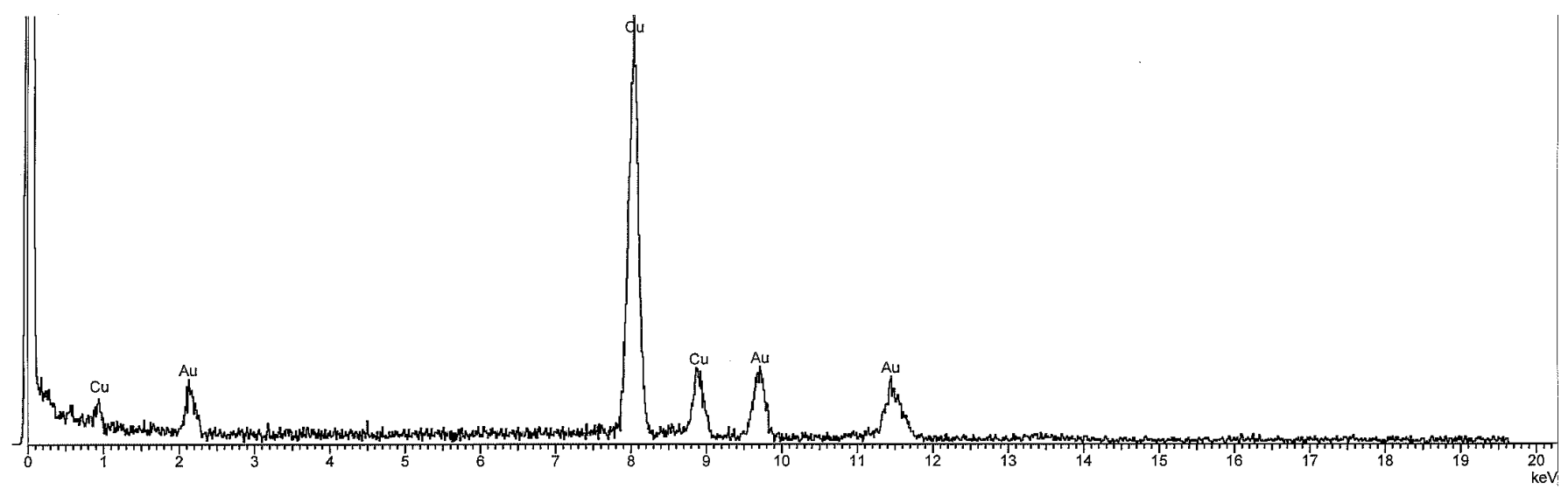

Figure 1. EDX spectrum of CuNPs/C.

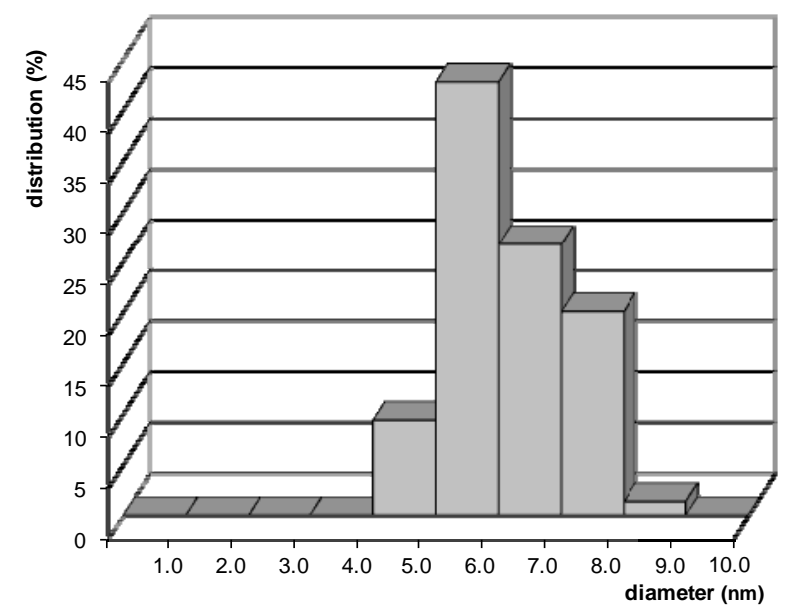

Figure 2. Size distribution of CuNPs/C determined by TEM. The sizes were determined for 75 nanoparticles selected at random.

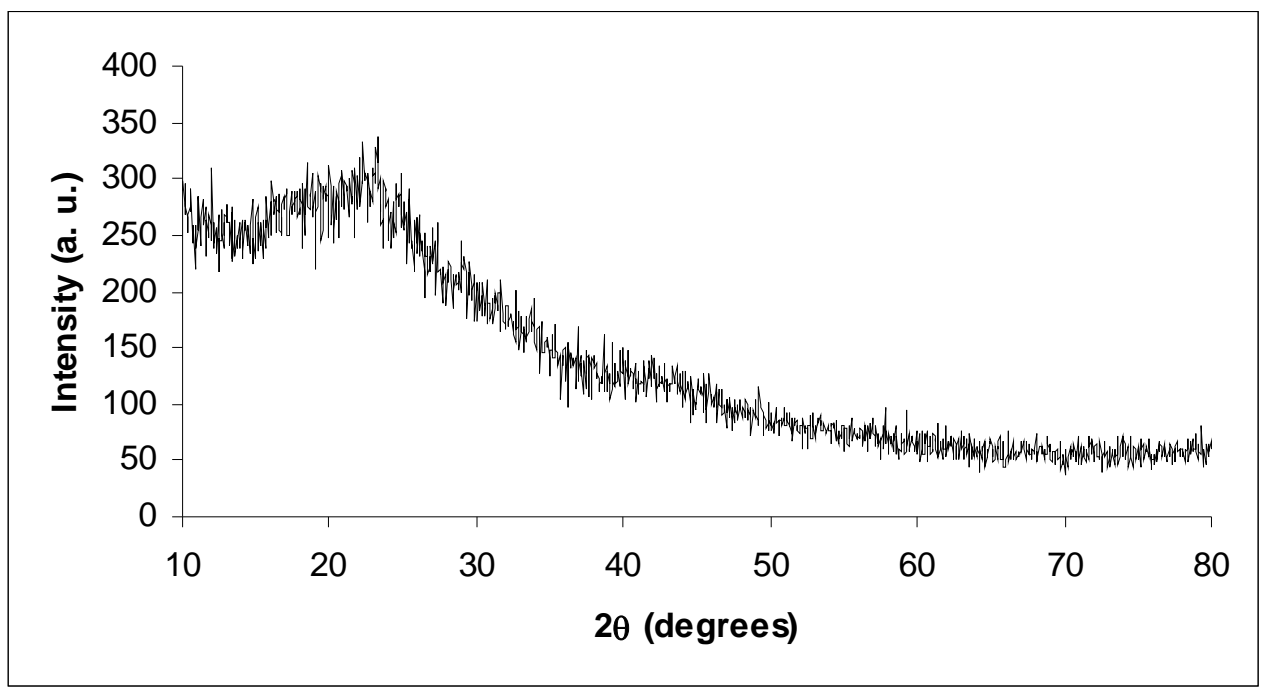

Figure 3. XRD spectrum of $\mathrm{CuNPs} / \mathrm{C}$. 


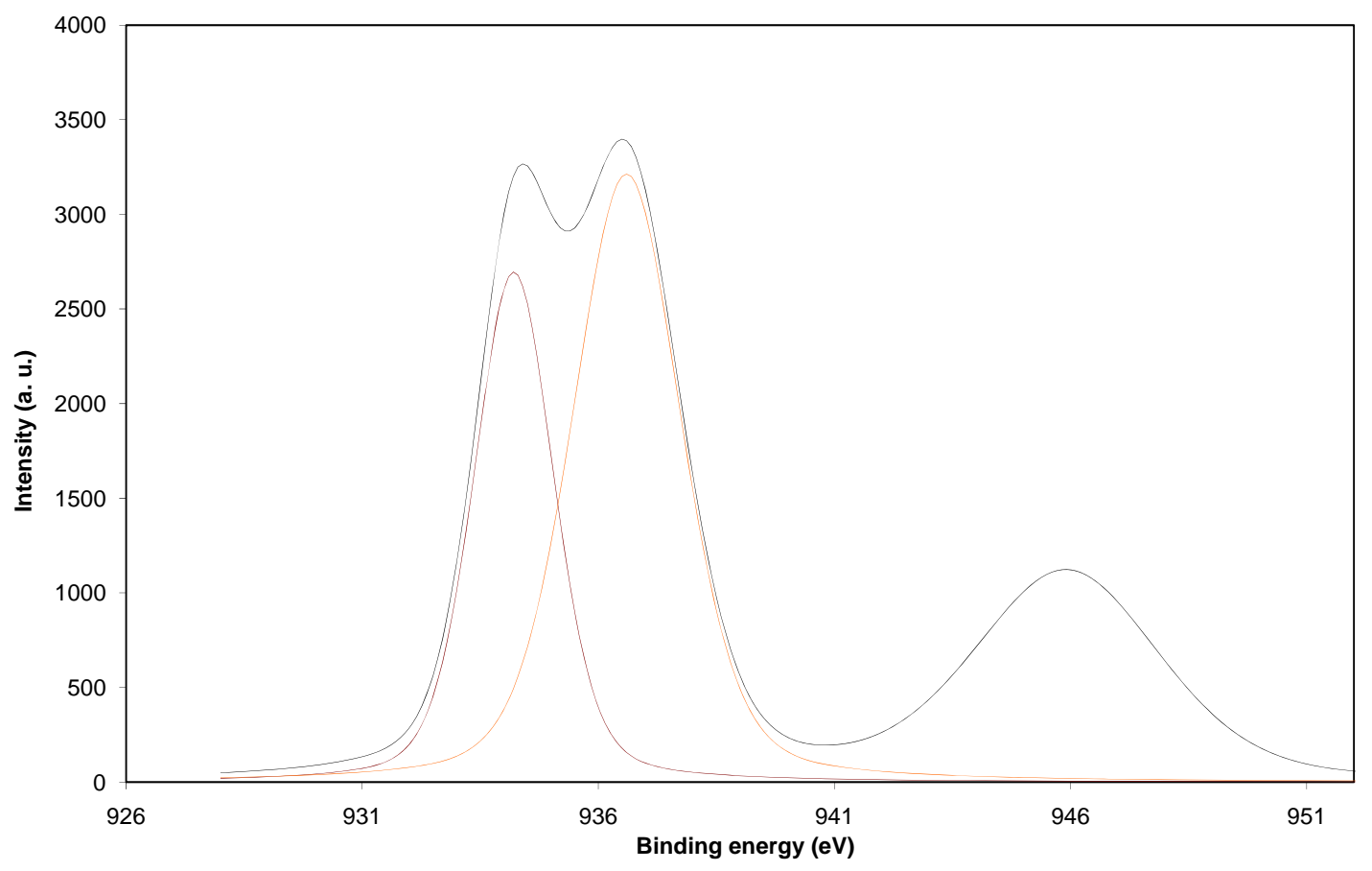

Figure 4. XPS spectrum of the $\mathrm{CuNPs} / \mathrm{C}$ at the $\mathrm{Cu} 2 \mathrm{p}_{3 / 2}$ level.

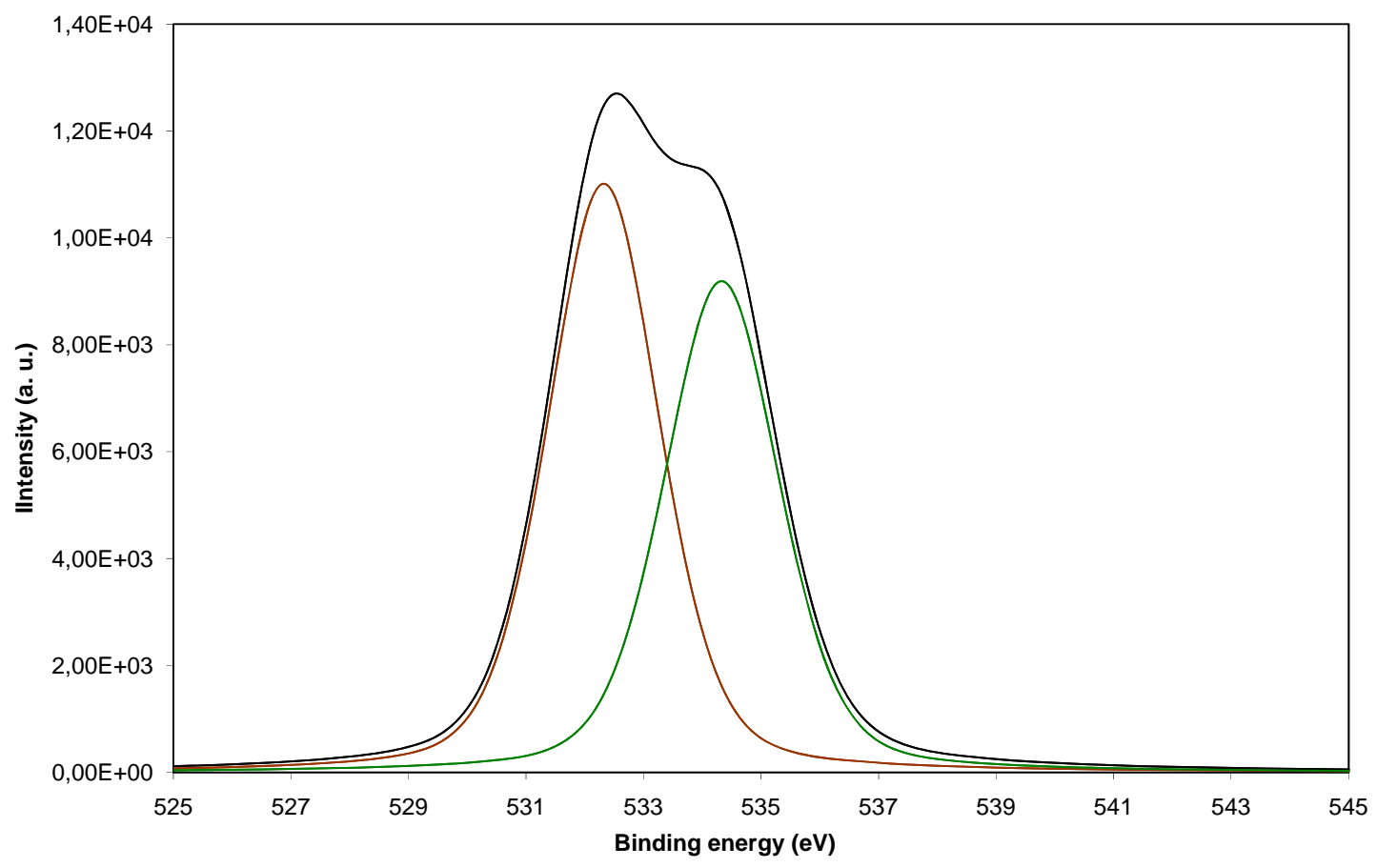

Figure 5. XPS spectrum of the $\mathrm{CuNPs} / \mathrm{C}$ at the $\mathrm{O}(1 \mathrm{~s})$ level. 


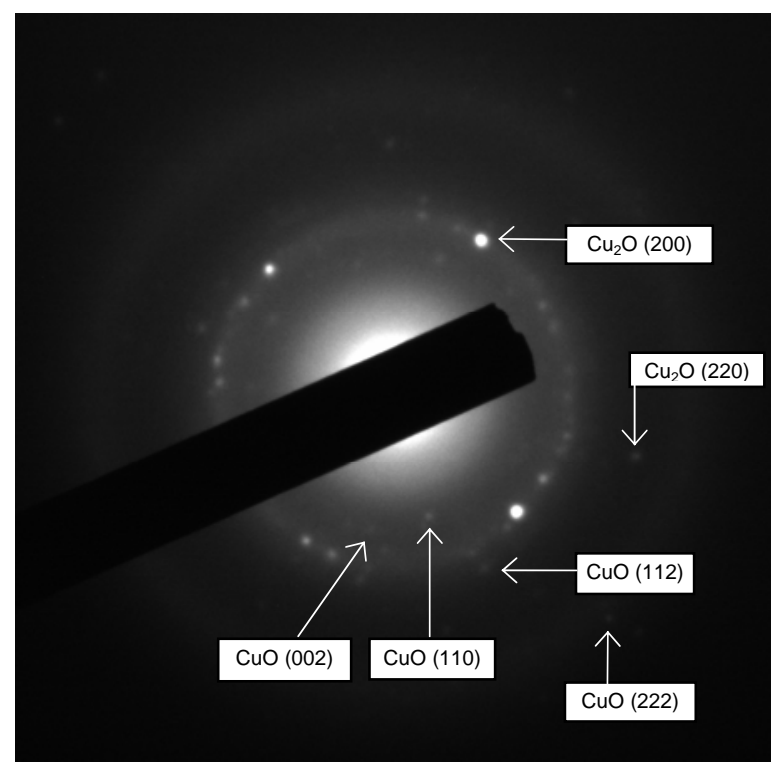

Figure 6. Selected area electron diffraction (SAED) pattern of the CuNPs/C.

Table 1. Three-component 1,3-dipolar azide-alkyne cycloaddition catalyzed by different copper catalysts. $^{[\mathrm{a}]}$

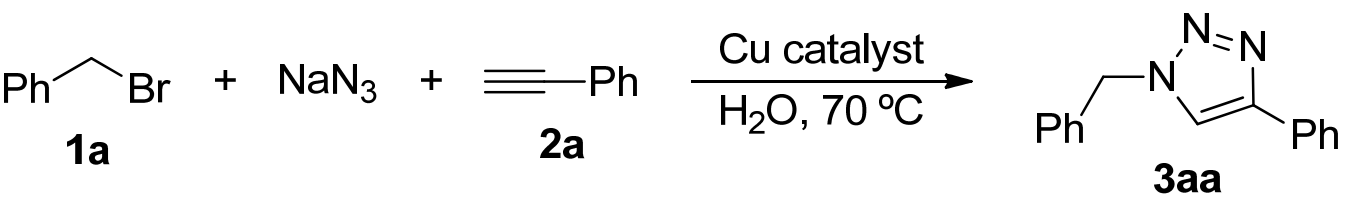

\begin{tabular}{lllll}
\hline Entry & Catalyst & {$[\mathrm{mol} \%]$} & Yield $(3 \mathrm{~h})[\%]^{[\mathrm{b}]}$ & ${\text { Yield }(24 \mathrm{~h})[\%]^{[\mathrm{b}]}}^{\circ}$ \\
\hline 1 & $\mathrm{Cu}$ & 10 & 52 & 52 \\
2 & $\mathrm{Cu}{ }_{2} \mathrm{O}$ & 10 & $90^{[\mathrm{c}]}$ & $90^{[\mathrm{c}][\mathrm{d}]}$ \\
3 & $\mathrm{CuO}$ & 10 & 69 & 88 \\
4 & $\mathrm{Cu}_{2} \mathrm{O}$ & 1 & 46 & 75 \\
5 & $\mathrm{CuO}$ & 1 & 53 & 78 \\
6 & $\mathrm{CuNPs} / \mathrm{C}$ & 0.5 & $100^{[\mathrm{e}]}$ & - \\
\hline
\end{tabular}

[a] Reaction conditions: 1 (1 mmol), 2 (1 mmol), $\mathrm{NaN}_{3}(1.1 \mathrm{mmol})$, catalyst in $\mathrm{H}_{2} \mathrm{O}(2 \mathrm{~mL})$ at $70{ }^{\circ} \mathrm{C}$. [b] GLC yield. [c] 10\% side products was obtained. [d] Reutilization furnished the corresponding triazole in $20 \%$ conversion after $24 \mathrm{~h}$ as a ca. $4: 1$ mixture of regioisomers. [e] Reutilized in five cycles with quantitative yield of triazole $3 a a$.

\section{General procedure for three-component 1,3-dipolar cycloaddition catalyzed by $\mathrm{CuNPs/C}$}

All reactions at $0.5 \mathrm{M}$ and $0.1 \mathrm{M}$ concentration were performed using tubes in a multi-reactor system, whereas reactions at $0.01 \mathrm{M}$ concentration were performed in a round-bottom flask equipped with a condenser. $\mathrm{NaN}_{3}(72 \mathrm{mg}, 1.1 \mathrm{mmol}$ ), the azide precursor (organic halide, diazonium salt, or epoxide, $1.0 \mathrm{mmol})$ and the alkyne $(1.0 \mathrm{mmol})$ were added to a suspension of $\mathrm{CuNPs} / \mathrm{C}(20 \mathrm{mg}, 0.5 \mathrm{~mol} \% \mathrm{Cu})$ 
in $\mathrm{H}_{2} \mathrm{O}(2 \mathrm{~mL})$. The reaction mixture was warmed to $70^{\circ} \mathrm{C}$ and monitored by TLC until total conversion of the starting materials. Water $(30 \mathrm{~mL})$ was added to the resulting mixture followed by extraction with EtOAc $(3 \times 10 \mathrm{~mL})$. The collected organic phases were dried with $\mathrm{MgSO}_{4}$, and the solvent was removed in vacuo to give the corresponding triazole, which did not require any further purification (compound 3ia was purified by column chromatography, hexane-EtOAc).

\section{Typical procedure for the CuNPs/C-catalyzed click reaction using anilines as azide precursors}

$\mathrm{NaN}_{3}$ (72 mg, $\left.1.1 \mathrm{mmol}\right)$, aniline (91 $\mu \mathrm{L}, 1.0 \mathrm{mmol}$.), $t$-BuONO (190 $\left.\mu \mathrm{L}, 1.6 \mathrm{mmol}\right)$ and phenylacetylene $(110 \mu \mathrm{L}, 1.0 \mathrm{mmol})$ were added to a suspension of $\mathrm{CuNPs} / \mathrm{C}(20 \mathrm{mg}, 0.5 \mathrm{~mol} \% \mathrm{Cu})$ in $\mathrm{H}_{2} \mathrm{O}(2 \mathrm{~mL})$. The reaction mixture was warmed to $70{ }^{\circ} \mathrm{C}$ and monitored by TLC until total conversion of the starting materials. Water $(30 \mathrm{~mL})$ was added to the resulting mixture followed by extraction with EtOAc $(3 \times 10 \mathrm{~mL})$. The collected organic phases were dried with $\mathrm{MgSO}_{4}$, and the solvent was removed in vacuo to give the corresponding triazole 5, which did not require any further purification.

\section{Typical procedure for the CuNPs/C-catalyzed click reaction using alkenes as azide precursors}

$\mathrm{NaN}_{3}$ (72 mg, $1.1 \mathrm{mmol}$ ), dimethyl(methylthio)sulfonium tetrafluoroborate (DMTSF, $196 \mathrm{mg}, 1$ $\mathrm{mmol})$, and cyclohexene $(101 \mu \mathrm{L}, 1.0 \mathrm{mmol})$ were added to a suspension of CuNPs/C (20 mg, 0.5 $\mathrm{mol} \% \mathrm{Cu})$ in $\mathrm{MeCN}(2 \mathrm{~mL})$ at room temperature under argon atmosphere. After stirring for $1 \mathrm{~h}$, phenylacetylene $(110 \mu \mathrm{L}, 1.0 \mathrm{mmol})$ was added. The reaction mixture was warmed to $70{ }^{\circ} \mathrm{C}$ and monitored by TLC until total conversion of starting materials. Water $(30 \mathrm{~mL})$ was added to the resulting mixture followed by extraction with EtOAc $(3 \times 10 \mathrm{~mL})$. The collected organic phases were dried with $\mathrm{MgSO}_{4}$, and the solvent was removed in vacuo to give the corresponding triazole 7, which was purified by column chromatography (hexane-EtOAc 8:2).

Compound characterization data: Triazoles $3 \mathbf{a a},{ }^{[1]} \mathbf{3 b a},{ }^{[2]} \mathbf{3 c a},{ }^{[3]} 3 \mathbf{d a},{ }^{[1]} \mathbf{3 e a},{ }^{[4]} \mathbf{3 f a},{ }^{[1]}$ 3ga $,{ }^{[5]} 3 \mathbf{h a},{ }^{[1]}$ $\mathbf{3 a b},{ }^{[6]} \mathbf{3 a c},{ }^{[7]} \mathbf{3 a d},{ }^{[8]} \mathbf{3 a e},{ }^{[1]} \mathbf{4},{ }^{[9]} \mathbf{5},{ }^{[1]}$ and $\mathbf{6}^{[10]}$ were characterized by comparison of their physical and spectroscopic data with those described in the literature. Data for the new compounds are given below:<smiles>c1ccc(-c2cn(CCc3c[nH]c4ccccc34)nn2)cc1</smiles>

\section{3-[2-(4-Phenyl-1H-1,2,3-triazol-1-yl)ethyl]-1H-indole (3ia)}

Yellow solid; m.p. 165.5-169.0 ${ }^{\circ} \mathrm{C} ; t_{\mathrm{r}} 27.13 \mathrm{~min} ; R_{\mathrm{f}} 0.55$ (hexane-EtOAc, 1:1). IR (KBr) $v=3394$, $3116,3089,1458,1258,1226,1193,743,765,694 \mathrm{~cm}^{-1} .{ }^{1} \mathrm{H}$ NMR $\left(300 \mathrm{MHz}, \mathrm{DMSO}-d_{6}\right): \delta=10.88(\mathrm{~s}$, 
1H), $8.58(\mathrm{~s}, 1 \mathrm{H}), 7.90-7.75(\mathrm{~m}, 2 \mathrm{H}), 7.70-7.53(\mathrm{~m}, 1 \mathrm{H}), 7.52-7.33(\mathrm{~m}, 4 \mathrm{H}), 7.20-6.92(\mathrm{~m}, 3 \mathrm{H}), 4.68$ $(\mathrm{t}, J=7.2 \mathrm{~Hz}, 2 \mathrm{H}), 3.34$ (t, $J=7.2 \mathrm{~Hz}, 2 \mathrm{H}) .{ }^{13} \mathrm{C}$ NMR $\left(75 \mathrm{MHz}, \mathrm{DMSO}-\delta_{6}\right): \delta=146.4,136.4,131.2$, $129.4,128.2$, 127.2, 125.5, 123.7, 121.8, 121.6, 118.9, 118.6, 111.9, 110.2, 50.5, 26.2. GC-MS (EI): $m / z(\%)=288(18)[\mathrm{M}]^{+}, 259(13), 156(21), 144$ (35), 143 (100), 131 (11), 130 (86), 115 (13), 103 (15), 102 (11), 77 (14). HRMS (EI): $m / z$ calcd. for $\mathrm{C}_{18} \mathrm{H}_{16} \mathrm{~N}_{4} 288.1375$; found 288.1384.<smiles>C[C@H]1CCCC[C@@H]1n1cc(-c2ccccc2)nn1</smiles>

\section{1-[(1 $\left.{ }^{*}, 2 R^{*}\right)-2-($ Methylthio)cyclohexyl]-4-phenyl-1H-1,2,3-triazole (7)}

Pale yellow solid; m.p. 128.0-130.1 ${ }^{\circ} \mathrm{C} ; t_{\mathrm{r}} 18.53 \mathrm{~min} ; R_{\mathrm{f}} 0.61$ (hexane-EtOAc, 7:3). IR $(\mathrm{KBr}) v=3119$, 3082, 2935, 2923, 2850, 1480, 1460, 1435, 1211, 1178, 1076, 1048, 974, 762, $697 \mathrm{~cm}^{-1}$. ${ }^{1} \mathrm{H}$ NMR (400 $\left.\mathrm{MHz}, \mathrm{CDCl}_{3}\right): \delta=7.88-7.84(\mathrm{~m}, 2 \mathrm{H}), 7.81(\mathrm{~s}, 1 \mathrm{H}), 7.46-7.35(\mathrm{~m}, 2 \mathrm{H}), 7.34-7.29(\mathrm{~m}, 1 \mathrm{H}), 4.24(\mathrm{td}, J$ $=11.2,4.2 \mathrm{~Hz}, 1 \mathrm{H}), 3.00(\mathrm{td}, J=11.2,4.2 \mathrm{~Hz}, 1 \mathrm{H}), 2.36-2.09(\mathrm{~m}, 3 \mathrm{H}), 1.99-1.86(\mathrm{~m}, 2 \mathrm{H}), 1.71(\mathrm{~s}$, 3H), 1.56-1.42 (m, 3H). ${ }^{13} \mathrm{C}$ NMR (100 MHz, $\left.\mathrm{CCl}_{3} \mathrm{D}\right): \delta=147.0,130.8,128.7,128.0,125.7,119.5$, 65.8, 50.4, 33.9, 33.3, 25.9, 25.1, 13.8. GC-MS (EI): $m / z(\%)=273(26)[\mathrm{M}]^{+}, 230(27), 196(12), 162$ (14), 129 (46), 128 (68), 117 (14), 116 (22), 102 (16), 89 (15), 81 (100), 79 (20), 61 (19). HRMS (EI): $m / z$ calcd. for $\mathrm{C}_{15} \mathrm{H}_{19} \mathrm{~N}_{3} \mathrm{~S} 273.1300$; found 273.1293.

\section{References}

[1] F. Alonso, Y. Moglie, G. Radivoy, M. Yus, Eur. J. Org. Chem. 2010, 1875-1884.

[2] P. Appukkuttan, W. Dehaen, V. V. Fokin, E. Van der Eycken, Org. Lett. 2004, 6, 4223-4225.

[3] B. Sreedhar, P. S. Reddy, Synth. Commun. 2007, 37, 805-812.

[4] P. S. Reddy, B. Sreedhar, Synthesis 2009, 4203-4207.

[5] T. Suzuka, K. Ooshiro, K. Kina, Heterocycles 2010, 81, 601-610.

[6] D. Raut, K. Wankhede, V. Vaidya, A. Deorukhkar, S. Bhilare, N. Darvatkar, G. Trivedi, M. Salunkhe, Catal. Commun. 2009, 10, 1240-1243.

[7] I. Jlalia, H. Elamari, F. Meganem, J. Herscovici, C. Girard, Tetrahedron Lett. 2008, 49, 6756-6758.

[8] J. Y. Kim, J. C. Park, H. Kang, H. Song, K. H. Park, Chem. Commun. 2010, 46, 439-441.

[9] K. Rajender Reddy, C. Uma Maheswari, K. Rajgopal, M. Laksmi Kantam, Synth. Commun. 2008, $38,2158-2167$.

[10] J. S. Clark, P. B. Hodgson, M. D. Goldsmith, L. J. Street, J. Chem. Soc., Perkin Trans. 1 2001, 3312-3324. 